\title{
BULLYING AND ITS IMPACT ON LONELINESS IN ADOLESCENTS: A META-ANALYSIS
}

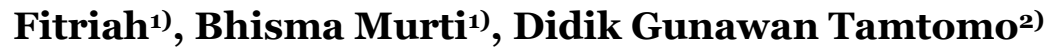 \\ 1)Masters Program in Public Health, Universitas Sebelas Maret \\ 2)Faculty of Medicine, Universitas Sebelas Maret
}

\begin{abstract}
Background: It is hypothesized that adolescents who suffered from traditional bullying and cyberbullying reported increasing levels of negative emotions (e.g., sadness and loneliness feelings over time). Empirical evidence has suggested that most adolescents who are bullied or cyberbullied tend to experience higher loneliness (attributed itself to a lack of social connectedness). This effect, in turn, served as a vulnerability factor for suicidal ideation. This study aimed to investigate bullying and its impact on loneliness in adolescents.

Subjects and Method: A systematic review and meta analysis was conducted using the PubMed, Science Direct, and Clinical Key, published from 2010 to 2020. The following search terms were used: "bullying and loneliness", "bullying and loneliness and adolescent and cross sectional study", "bullying and loneliness and adolescent and cross sectional study and adjusted odd ratio". The inclusion criteria were full-text and observational study. The systematic review was carried out according to the PRISMA guidelines. Data analyses were performed using RevMan 5.3.

Results: The meta-analysis included 14 studies from Indonesia, Tanzania, Vietnam and Malaysia. Bullying elevated the risk of loneliness feelings in adolescents $(\mathrm{aOR}=$ 1.92; CI 95\%= 1.49 hingga 2.49; $\mathrm{p}<0.001$ ).
\end{abstract}

Conclusion: Bullying elevates the risk of loneliness feelings in adolescents.

Keywords: bullying, loneliness, adolescents

\section{Correspondence:}

Fitriah. Masters Program in Public Health, Universitas Sebelas Maret. Jl. Ir. Sutami 36A, Surakarta 57126, Central Java. Email: fitriahbaharuddin@gmail.com. Mobile: +6282350701936 . 